\title{
A comparative study of structure of vertical motions in the lower troposphere over Pune, a tropical Indian station in March 2004 and 2005 using Wind Profiler data
}

\author{
S. M. Deshpande and P. Ernest Raj \\ Indian Institute of Tropical Meteorology, Pashan Road, Pune - 411008, India \\ Received: 4 April 2007 - Revised: 21 September 2007 - Accepted: 3 October 2007 - Published: 6 November 2007
}

\begin{abstract}
An extended heat wave condition affected Pune $\left(18.31^{\circ} \mathrm{N}, 73.58^{\circ} \mathrm{E}\right)$, India and surrounding region during the pre-monsoon month of March 2004, when surface temperatures were observed to be above normal. In contrast, March 2005 showed a long spell of below normal temperatures. The vertical velocity measurements from UHF (404 MHz) Wind Profiler at Pune have been used to understand the role of vertical motions in the lower troposphere in maintenance of long spells of above (in March 2004) and below (in March 2005) normal surface temperatures over the station. The altitude profiles of vertical wind velocities showed different behavior in the two contrasting years 2004 and 2005. It is observed that for a major part of the month and at all heights, downward motions (subsidence) dominate during March 2004. Strong downward motions persisted for spells of 2 to 3 days when high surface temperatures (above $38^{\circ} \mathrm{C}$ ) were recorded over this station. A positive relation between surface temperature anomalies and depth of subsidence points to the role of subsidence. March 2005 showed the persistence of upward motion for longer time duration during morning hours which prevented the surface temperatures from reaching high values with weak subsidence during afternoon hours. This is supported by observation of more frequent and organized thermal plumes extending right into the free troposphere. There are distinct episodes of advective warmings during March 2004 while March 2005 showed weak or absence of temperature advection from north. Hence a combination of meridional transport of heat and persistent subsidence in the lower troposphere seemed to have led to recording of above normal surface temperatures during March 2004 over the station.
\end{abstract}

Keywords. Meteorology and atmospheric dynamics (Convective processes; Tropical meteorology; Instruments and techniques)

Correspondence to: P. Ernest Raj

(ernest@ tropmet.res.in)

\section{Introduction}

Heat wave is a well known surface meteorological phenomenon that constitutes an abnormally hot weather for a substantial duration. This phenomenon belongs to the atmosphere's synoptic scale circulation. Heat wave is one of the hazardous weather conditions in the pre-monsoon season (March-May) and early part of South West monsoon season (June-September) over the Indian subcontinent. In USA, the Weather Channel uses a criterion to specify a heat wave condition which includes a minimum of ten States with maximum temperature greater than $32^{\circ} \mathrm{C}$ and the temperatures must be at least five degrees above normal in parts of that area for at least two or more days. The favorable factors for heat wave conditions to occur over a particular region are a large region of warm dry air prevailing in the surrounding of that region and appropriate flow pattern for transporting hot air into the region, absence of moisture over a depth of atmospheric column, and large amplitude anti cyclonic flow in the vertical levels above the place (Chaudhury et al., 2000).

Black et al. (2004) have discussed the factors contributing to the summer 2003 European heat wave by examining the large-scale atmospheric flow and the regional heat budget from ECMWF analyses and measurements of the surface energy budget at Reading, UK. They related the extreme temperatures and lack of precipitation in Europe from May to August 2003 to persistent anti cyclonic conditions throughout the period. Grazzini et al. (2003) have also discussed the European 2003 heat wave in a more quantitative way. Balafoutis and Makrogiannis (2001) have analyzed a heat wave phenomenon over Greece during August 1999 mainly from synoptic point of view and examined its implications on tourism and recreation. Their study showed that large scale downward vertical velocities (maximum value $+4 \mathrm{hPa} / \mathrm{h}$ ) dominated over central Mediterranean and Balkan Peninsula which resulted in warmer advection because of adiabatic heating, giving rise to the observed intense temperature increase at the surface and the absolute stability in the troposphere. 
Table 1. Technical specifications of the Wind Profiler system at Pune.

\begin{tabular}{ll}
\hline Operating frequency/bandwidth & $404.37 \mathrm{MHz} / \pm 0.250 \mathrm{MHz}$ \\
Pulse repetition period & $60 \mu \mathrm{s} / 160 \mu \mathrm{s}$ \\
Pulse width & $2 \mu \mathrm{s}$ (uncoded); $16 \mu \mathrm{s}$ (8 bit coded) \\
Peak transmit power & $16 \mathrm{KW}$ \\
Duty ratio & $10 \%$ Maximum \\
Number of coherent integration & 76 \\
Number of incoherent integration & 10 \\
Number of FFT points & $256 / 512$ (selectable) \\
\hline
\end{tabular}

Rodwell and Hoskins (2001) showed that in the tropics, the predominant balance is between the diabatic term and the mean vertical advection term. This reflects a balance between diabatic warming (cooling) and adiabatic cooling (warming) due to ascent (descent) in a local Hadley circulation. The adiabatic descent which has a warm thermal anomaly associated with it, would inhibit latent heat release and increase radiative cooling. The effect of these changes would be net cooling of the atmosphere and hence a probable increase in the strength of the descent. The key factor in the process of elevated surface temperatures seems to be this subsidence or in more general terms, the direction and magnitude of "vertical velocity". Vertical wind velocity generally being smaller in magnitude compared to horizontal winds, can not be measured by simple conventional techniques and is usually estimated using pressure-wind relationships. Such estimated vertical velocities are found to contain large errors (Holton, 1992) and are therefore seldom used for detailed analysis and studies. Direct measurements of the vertical velocities became available with the advent of UHF/VHF Wind Profiler radars. Such a UHF system is currently in operation at Pune, $\left(18.31^{\circ} \mathrm{N}, 73.58^{\circ} \mathrm{E}\right)$ a tropical Indian station. Pune is an urban center located about $100 \mathrm{~km}$ from the coast of Arabian Sea on the west coast of peninsular India. The station altitude is $559 \mathrm{~m}$ above mean sea level. In a previous paper Deshpande et al. (2007) have discussed the possible relationship between the surface temperature anomaly and the depth of the atmospheric column over which subsidence occurs in the pre-monsoon month. In the present study, high spatio-temporal resolution Wind Profiler measured vertical velocities have been used to study the nature of subsidence in the lower troposphere during contrasting pre-monsoon months (March) of 2004 and 2005 which showed different patterns of surface temperatures.

\section{Wind Profiler system and data}

\subsection{Wind Profiler}

A $404 \mathrm{MHz}$ UHF Wind Profiler/Radio Acoustic Sounding System (WP/RASS) has been in continuous operation at India Meteorological Department (IMD), Pune since June 2003. The system has typical height coverage extending from about $1 \mathrm{~km}$ to about $6-10 \mathrm{~km}$, depending on weather conditions, with a height resolution of $300 \mathrm{~m}$. The Wind Profiler has power aperture product (average) of around $2 \times 10^{5}$ watt $\mathrm{m}^{2}$. It has two off-zenith beams; East and North, and one Zenith beam setting, enabling measurements of all three components viz. zonal, meridional and vertical components of a vector wind. The return signals in radar system depend on the backscatter through Bragg scattering from turbulent fluctuations in radio refractive index in the neutral atmosphere which are caused by clear air density fluctuations and or also by Fresnel scatter (Atlas, 1990; Gage, 1980). The mean wind at any given height carries these fluctuations/irregularities and thus the latter (and hence the backscatter signal) becomes a tracer of the mean wind velocity at that height. One set of vector wind profiles is obtained in about $6 \mathrm{~min}$ depending on the dwell time utilized for each radial beam measurement. Some technical specifications of the Pune Wind Profiler system are given in the Table 1. System details inclusive of quality control procedure for data, validation of the Wind Profiler data products and comparisons with the other conventional instruments viz. Radiosonde/Rawinsonde and pilot balloon are given in Pant et al. (2005).

\subsection{Data}

The radial velocity values for each beam obtained, for a given range bin, over the total observation period are passed through a process of consensus averaging as outlined by Fischer and Bolles (1981) and Barth (1995), which helps to eliminate to a large extent the effects of transient interfering signals, outliers and random spiky noise. The radial velocities are sampled at 2 to $6 \mathrm{~s}$ intervals depending on system pulse repetition period, number of coherent, incoherent integrations and number of FFT (Fast Fourier Transform) points. The averaged radial velocities are then used to calculate the zonal, meridional and vertical wind velocity components of the mean wind in the hour of the observation. A vertical wind profile is thus obtained typically in five to six minutes.

In the present study, the vertical velocity data from $1.05 \mathrm{~km}$ to $6 \mathrm{~km}$ measured by the Wind Profiler in the months of March 2004 and March 2005 is utilized. Hourly averaged vertical velocity profiles were obtained four times a day viz. at 08:00, 11:00, 14:00 and 17:00 IST (Indian Standard Time). The profiler velocities are presented in meteorological convention i.e. positive vertical velocity indicating upward motion. The data of daily maximum surface temperatures of 
Pune and stations located at different northern latitudes in the months of March 2004 and 2005 have been collected from the Indian Daily Weather Report (IDWR) published by India Meteorological Department.

\section{Results and discussion}

Grid point data of monthly mean surface temperature (day's maximum) for the month of March for the 56-year period from 1948 to 2004 for the Indian subcontinent region $\left(60^{\circ} \mathrm{E}\right.$ to $100^{\circ} \mathrm{E}$ and $0^{\circ} \mathrm{N}$ to $40^{\circ} \mathrm{N}$ ) has been taken from NCEP Reanalysis grid-point data set and a climatological mean has been prepared for the pre-monsoon month of March. The deviations (anomalies) in surface maximum temperature during March 2004 and during March 2005 from this climatological mean have then been computed. These anomalies have been plotted separately for the years 2004 and 2005 and shown as contour plots in Fig. 1. March 2004 (top panel) showed largest positive anomaly of magnitude $5.0^{\circ} \mathrm{C}$ over the extreme northwest of the sub-continent (around $32^{\circ} \mathrm{N}$, $66^{\circ} \mathrm{E}$ ) and $2.0-2.5^{\circ} \mathrm{C}$ above climatological mean over the Pune region (location of the Wind Profiler). Barring a small region over the east peninsular India, the anomalies were positive almost all over the Indian region. In March 2005 (bottom panel), the positive temperature anomalies of magnitude greater than $1.0^{\circ} \mathrm{C}$ were found over northern Indian region and remaining parts of India showed very small positive anomalies. While over the Pune region a negative anomaly of $0.5^{\circ} \mathrm{C}$ was seen in March 2005. The overall mean maximum surface temperature distribution (spatial pattern) during March over the Indian region itself is observed to be different during the two years.

Vector winds at $850 \mathrm{hPa}$ for the Indian region $\left(5^{\circ}-40^{\circ} \mathrm{N}\right.$; $60^{\circ}-100^{\circ} \mathrm{E}$ ) at $2.5^{\circ} \times 2.5^{\circ}$ grid-point taken from NCEP Reanalysis during March 2004 and March 2005 are shown plotted in Figs. 2a and b, respectively. On comparison it is seen that a strong meridional component in horizontal winds over the north central region of India is seen during March 2004 at latitudes greater than $20^{\circ} \mathrm{N}$ (winds are predominantly north westerly) and there exists an anti-cyclone over the central Indian region (over Pune and surrounding region). Winds are mostly westerly during March 2005 and anti-cyclone is not over the continental region but slightly shifted to the west over to the Arabian Sea region. Black et al. (2004) have also shown that the extreme temperatures in Europe from May to August 2003 were related to the persistent anticyclonic conditions. The geopotential height anomalies over the Pune region were observed to be slightly higher during March 2004 compared to that during March 2005.

The time series of observed daily maximum surface temperatures over Pune in the month of March for the above two years (2004 and 2005) is shown in Fig. 3. The day to day variation of the climatological mean surface temperature (daily maximum) for the same station is also shown plot-
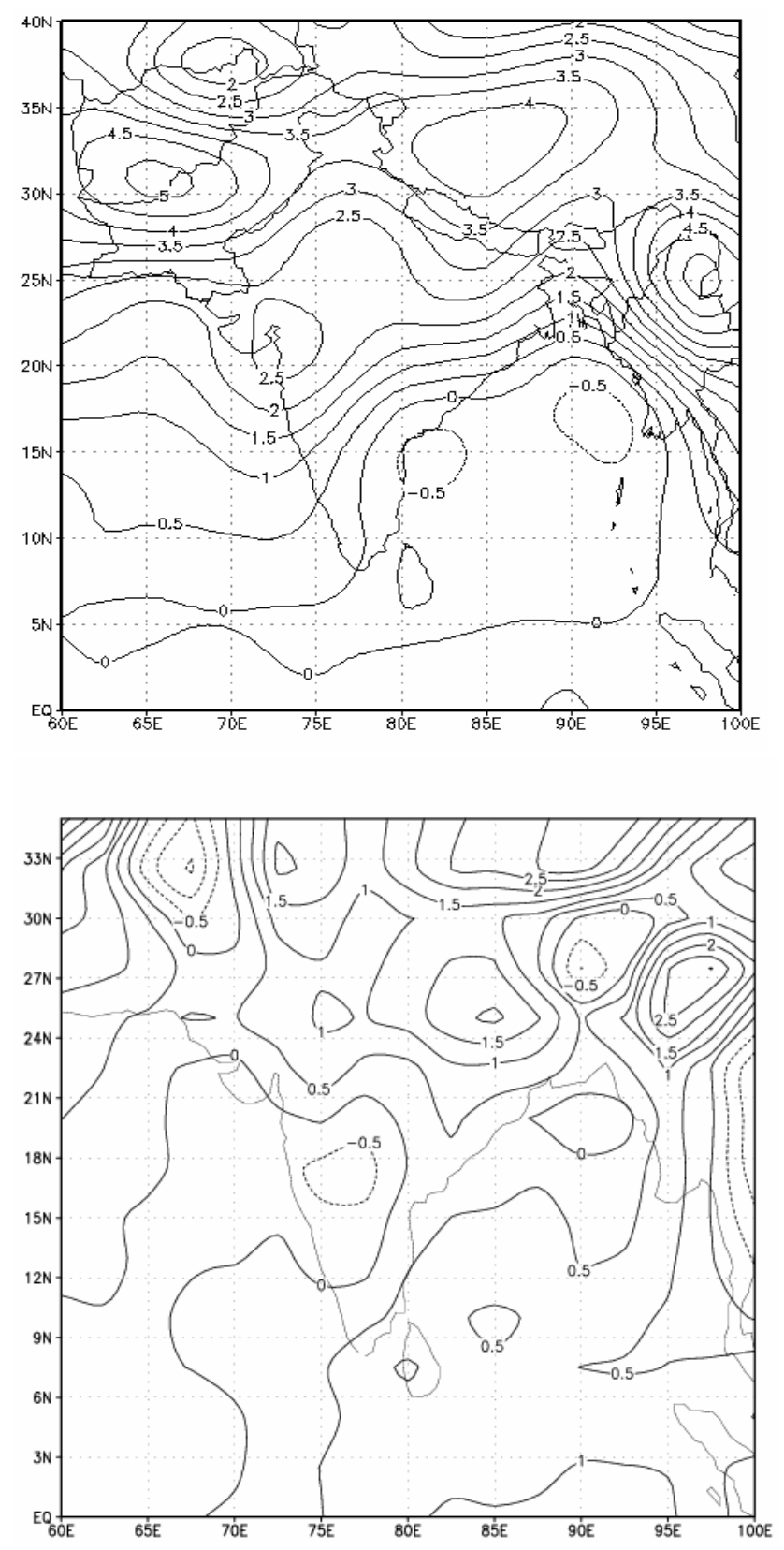

Fig. 1. Spatial distribution of anomalies of the surface temperatures $\left({ }^{\circ} \mathrm{C}\right)$ during March 2004 (top panel) and March 2005 (bottom panel) over the Indian subcontinent region.

ted in the same figure for comparison. Surface maximum temperatures are lesser on almost all the days in 2005 compared to 2004. It is further seen that on each and every day of March 2004 the daily maximum temperature was above normal while it was below normal for many days during the month of March 2005. The major factors governing the variability of surface temperature are solar radiation, advection and subsidence. To examine the role of the advection and subsidence on the surface temperature variability over Pune 
Vector wind at $850 \mathrm{hPa}$, March 2004

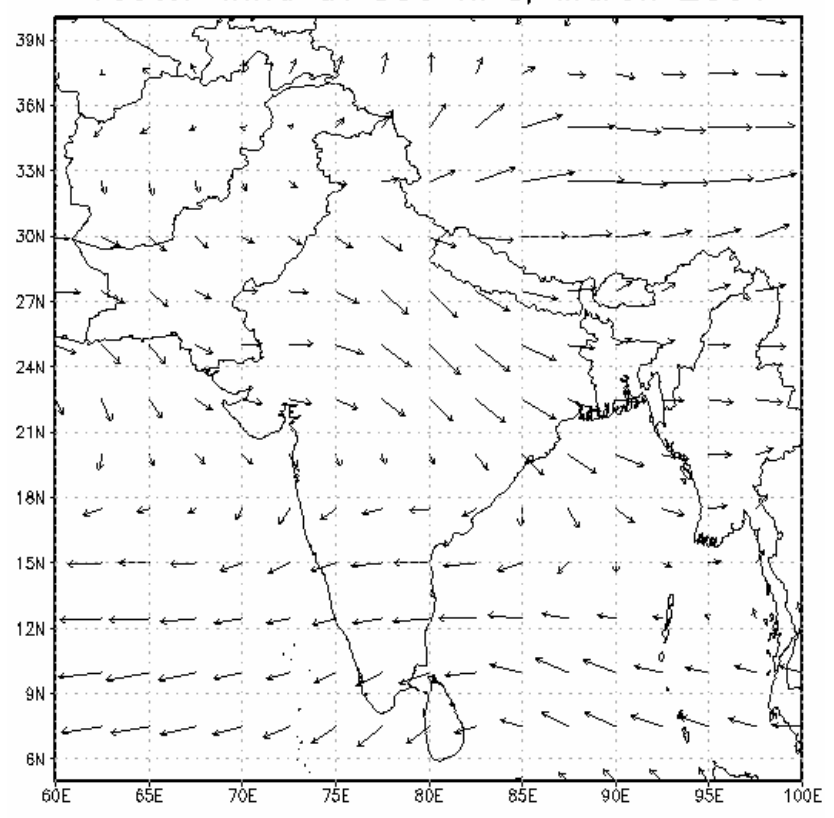

(a)

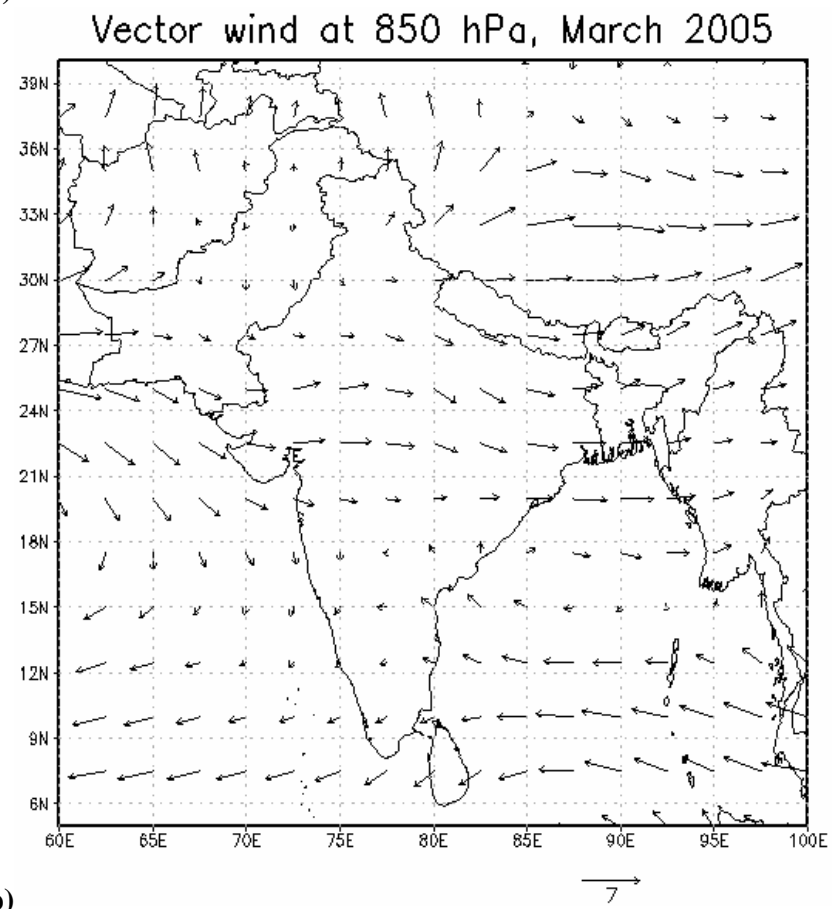

Fig. 2. The $850 \mathrm{hPa}$ vector winds over the Indian continental region $\left(5^{\circ}-40^{\circ} \mathrm{N} ; 60^{\circ}-100^{\circ} \mathrm{E}\right)$ during (a) March 2004 and during (b) March 2005 .

during the month of March for the two years, surface level temperatures at few Indian stations north of Pune and vertical profiles of vertical wind velocity (Wind Profiler derived) at Pune have been taken and the variations have been presented

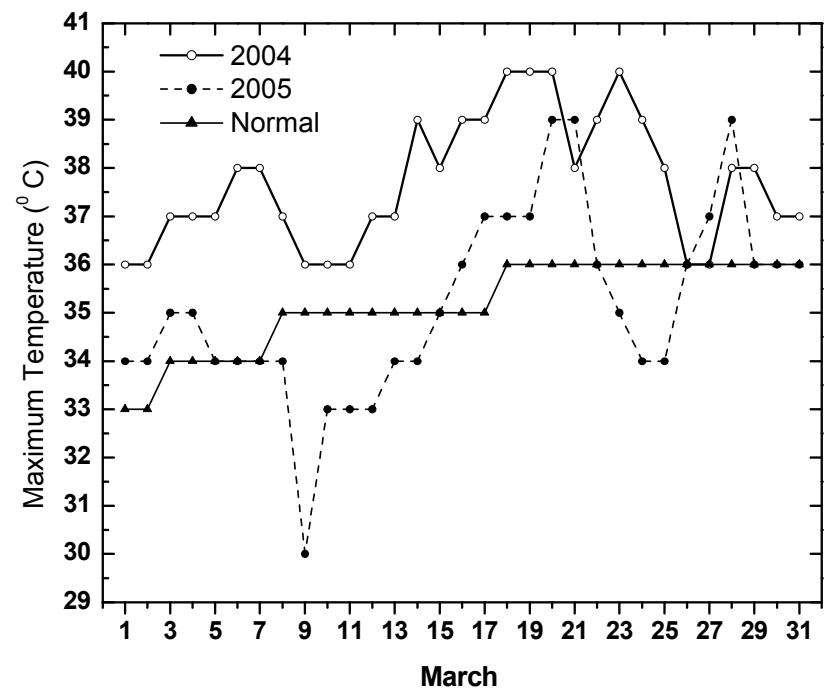

Fig. 3. Day-to-day variation of maximum surface temperature over Pune during March 2004 (open circle) and March 2005 (filled circle). The line connected by triangles shows the climatological mean value for March.
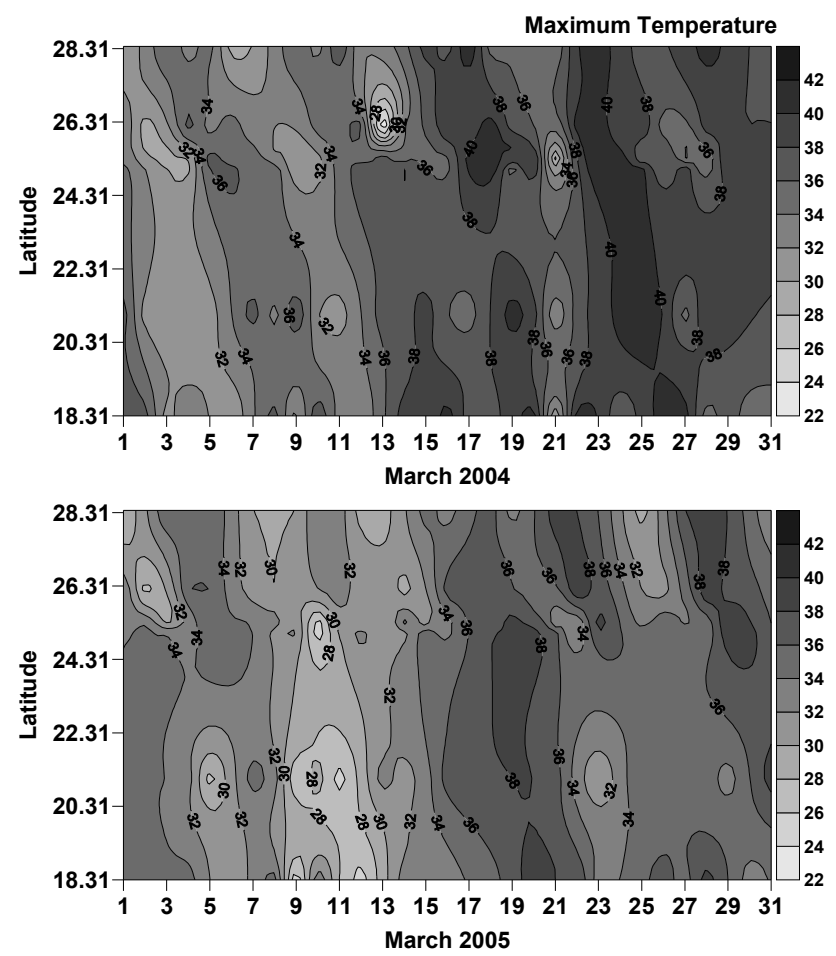

Fig. 4. Latitude-time cross sections of the daily maximum surface temperature $\left({ }^{\circ} \mathrm{C}\right)$ distribution over Indian longitudes in March 2004 (top panel) and March 2005 (bottom panel).

and discussed in the following sections. Other supporting data of signal-to-noise ratio from Wind Profiler, Outgoing Long wave Radiation (OLR), potential temperature etc. have also been used in the discussion. 


\subsection{Role of advection in surface temperature variability}

To examine the effect of advection on the surface level temperatures, the latitude-time cross section of the maximum temperature for March 2004 and March 2005 has been prepared by collecting daily maximum surface temperature data from Indian Daily Weather Reports (IDWRs) for some Indian stations located at different latitudes north of Pune. The stations considered here are New Delhi $\left(28.37^{\circ} \mathrm{N}, 77.12^{\circ} \mathrm{E}\right)$, Jodhpur $\left(26.18^{\circ} \mathrm{N}, 73.1^{\circ} \mathrm{E}\right)$, Allahabad $\left(25.28^{\circ} \mathrm{N}, 81.44^{\circ} \mathrm{E}\right)$, Varanasi $\left(25.20^{\circ} \mathrm{N}, 83.54^{\circ} \mathrm{E}\right)$, Nagpur $\left(21.09^{\circ} \mathrm{N}, 79.03^{\circ} \mathrm{E}\right)$ and Pune $\left(18.31^{\circ} \mathrm{N}, 73.58^{\circ} \mathrm{E}\right)$. Figure 4 shows this latitudetime cross section during March for the years 2004 (top panel) and 2005 (bottom panel). Here zonal homogeneity in the temperature distribution is assumed. The downward sloping of temperature isolines during March 2004 (top panel) indicates north to south transport of heat at the surface. Higher temperatures are developed first in the northern latitudes and gradually spread towards the southern latitudes. Three episodes of such southward migration can be seen in the year 2004. In the first one i.e. on 4 March, a region of high temperature developed around $28^{\circ} \mathrm{N}$ latitude and after 5 days i.e. on 9 March, higher temperatures are observed at around $18^{\circ} \mathrm{N}$. The second episode is observed from 16 to 20 March and the third episode is from 23 to 27 March. Thus there was an advection of hot/warm air from northern to southern latitudes (i.e. from North India to central peninsula). The advection could be mainly caused by the prevailing northerly westerly winds in the western part of the surface low-pressure area. The effect of the advection is to make the temperature distribution uniformly high in March 2004. Figure 4 (bottom panel) shows the latitude-time cross-section of surface maximum temperature during the month of March 2005 . Here the temperature isolines are seen to be nearly vertical or occasionally slightly downward sloping, indicating a weak meridional temperature advection from north to south. Thus the existence of a north to south meridional advection of warm air seems to be one of the causes for observation of higher surface temperatures at Pune and surroundings during March 2004. The $850 \mathrm{hPa}$ vector winds over the Indian continental region during March 2004 (Fig. 2a) show a stronger meridional component compared to that during March 2005 (Fig. 2b) supporting the meridional advection of warm air.

\subsection{Role of subsidence in the surface temperature variabil- ity}

The monthly mean vertical profiles of vertical wind velocity at the four individual observational hours (i.e., 08:00, 11:00, 14:00 and 17:00 IST) for March 2004 (open circles) and for March 2005 (closed circles) have been computed and shown in Figs. 5a to d. In Fig. 5a, it is seen that in the morning hour i.e. at 08:00 IST, in March 2004, an upward motion of the order of $5-10 \mathrm{~cm} / \mathrm{s}$ occurs in the altitude range $1 \mathrm{~km}$ to $3 \mathrm{~km}$ and a subsidence (downward) motion of the order
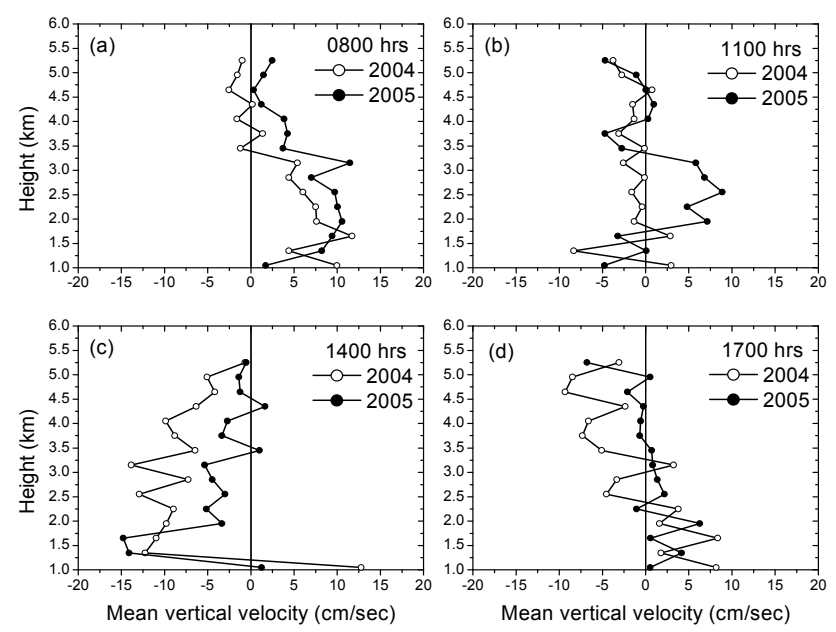

Fig. 5. Vertical distributions of Wind Profiler-derived monthly mean vertical velocity $(\mathrm{cm} / \mathrm{s})$ at four observational hours, (a) 08:00 h, (b) 11:00 h, (c) 14:00 h, and (d) 17:00 h IST, in March 2004 and 2005.

of $1-2 \mathrm{~cm} / \mathrm{s}$ prevails in the layer $3.5 \mathrm{~km}$ to $5.5 \mathrm{~km}$. The upward motion in the lower levels may be due to ground heating by solar radiation. In March 2005, it is seen that the upward motion of the order of $3-12 \mathrm{~cm} / \mathrm{s}$ occurred at all vertical levels from surface to $6 \mathrm{~km}$ in the lower atmosphere. The order of magnitude of the upward motion is also higher in March 2005 compared to that in March 2004. In March 2004, by 11:00 IST (Fig. 5b), the subsidence (downward motion) extends to almost the entire lower troposphere while in March 2005 strong upward motion still persisted in the $2 \mathrm{~km}$ to $3.5 \mathrm{~km}$ range. In March 2004 in the afternoon hours i.e. at 14:00 IST (Fig. 5c), subsidence has intensified to $10 \mathrm{~cm} / \mathrm{s}$ in magnitude. While in March 2005 also subsidence can be seen prevailing in the vertical at all levels but at relatively reduced magnitude compared to that in 2004. At 17:00 IST (Fig. 5d) in March 2004 there was upward motion in the lower levels extending up to $2 \mathrm{~km}$, but subsidence motion continued to prevail in the layer above $2.5 \mathrm{~km}$. While in March 2005 upward motion of small magnitude can be seen. Thus even on a monthly average scale, March 2004 shows relatively stronger descending motions for a major part of daytime in comparison to that seen during March 2005. It is also pointed out here that there is significant diurnal (daytime) evolution in the vertical structure of vertical wind velocity in the lower troposphere of this tropical station in the pre-monsoon month of March.

To have a more comprehensive understanding of temporal variations in vertical velocity, the day-to-day variability of vertical velocity in the two years is shown in Fig. 6 as time-height cross section (upper panel for March 2004, lower panel for March 2005). A continuous data set of all four observation hours during daytime (i.e. four vertical profiles each day) was considered here. However such data was available only from 10 March onwards in the year 2004 and 

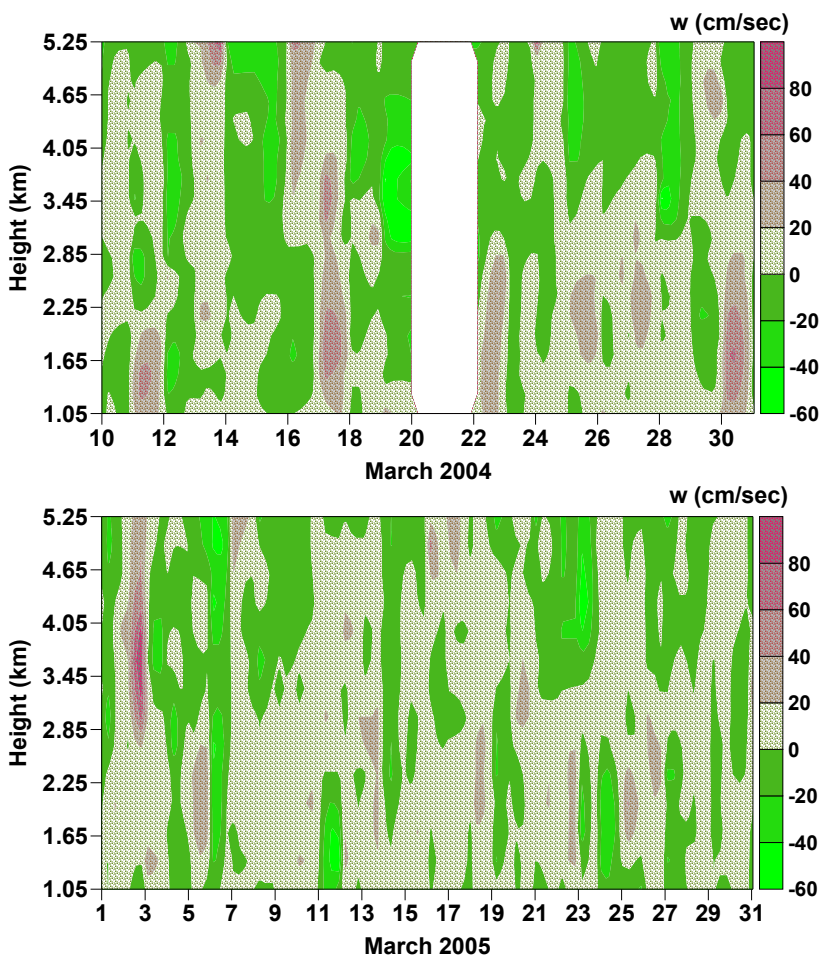

Fig. 6. Time-height cross sections of Wind Profiler-derived vertical velocities in March 2004 (top panel) and in March 2005 (bottom panel).

on all the 31 days during March 2005. In both the panels time-height regions when upward motions prevailed are shown spotted and regions of subsidence were shown as plain green shaded regions. Non-availability of data on 20 and 21 March 2004 is indicated by a blank region. It is observed that for a major part of the month and at all heights downward motions dominate during March 2004. Strong downward motions existed during the periods $14-16,18-20$ and 23-25 March 2004. These are the days when high surface temperatures (above $38^{\circ} \mathrm{C}$ ) were recorded over this station (Fig. 3). Again when upward motions prevailed in the 1 to $3.5 \mathrm{~km}$ height range, surface temperature was lower and equal to climatological mean. While in March 2005, ascending motions dominate and were extended to higher altitudes during the whole month. From 7 to14 March 2005, there is decreasing temperature trend in surface temperature when the observed vertical velocities are predominantly upward.

The daily maximum temperatures for March 2004 (shown in Fig. 3) are taken and daily departures from the climatological normals are first computed. During March there was a progressive increase in the incoming solar radiation due to change in solar declination. The incoming solar radiation for Pune has been computed using the formulation given by Racz and Smith (1999). The effect of solar radiation on the variability of the temperature has been removed by fitting a straight line to the daily departures in tempera-

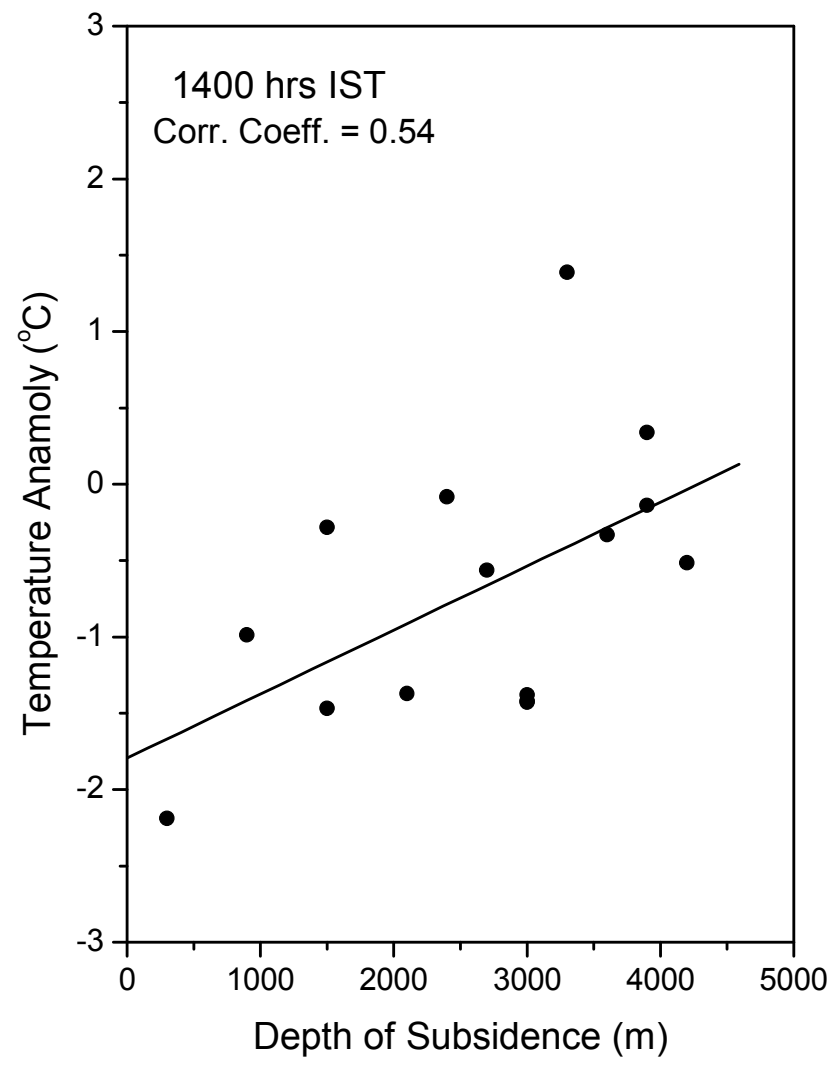

Fig. 7. Scatter plot of temperature anomaly and depth of subsidence during March 2004.

ture and subtracting the contribution of solar radiation heating obtained through the equation of the fitted straight line. Thus the residual temperature anomalies can be attributed to be mainly due to subsidence, assuming that during this period the effects of advection are small and constant. The total depth of the column where downward motions occur in each hourly profile of vertical motions during March 2004 is computed. Since the surface maximum temperatures occur in the afternoon hours, the daily vertical profile of vertical velocity at 14:00 IST is taken to get the daily depth of subsidence. The scatter plot of temperature anomalies and depth of subsidence and the best fit line are shown in the Fig. 7. A positive relation between temperature anomalies and depth of subsidence during March 2004 is seen providing a further evidence of the role of subsidence.

Thus the current analysis shows that upward and downward motions are closely associated with the cooling and warming effects on the surface heat budget and hence on the surface temperatures. Balafoutis and Makrogiannis (2001) have also shown that large scale downward vertical velocities contributed to the observed intensive temperature rise at the surface over Greece. The upward motion mixes the air in the lowest levels, transporting heat from lower layers to upper layers and thus tries to prevent the surface temperature 


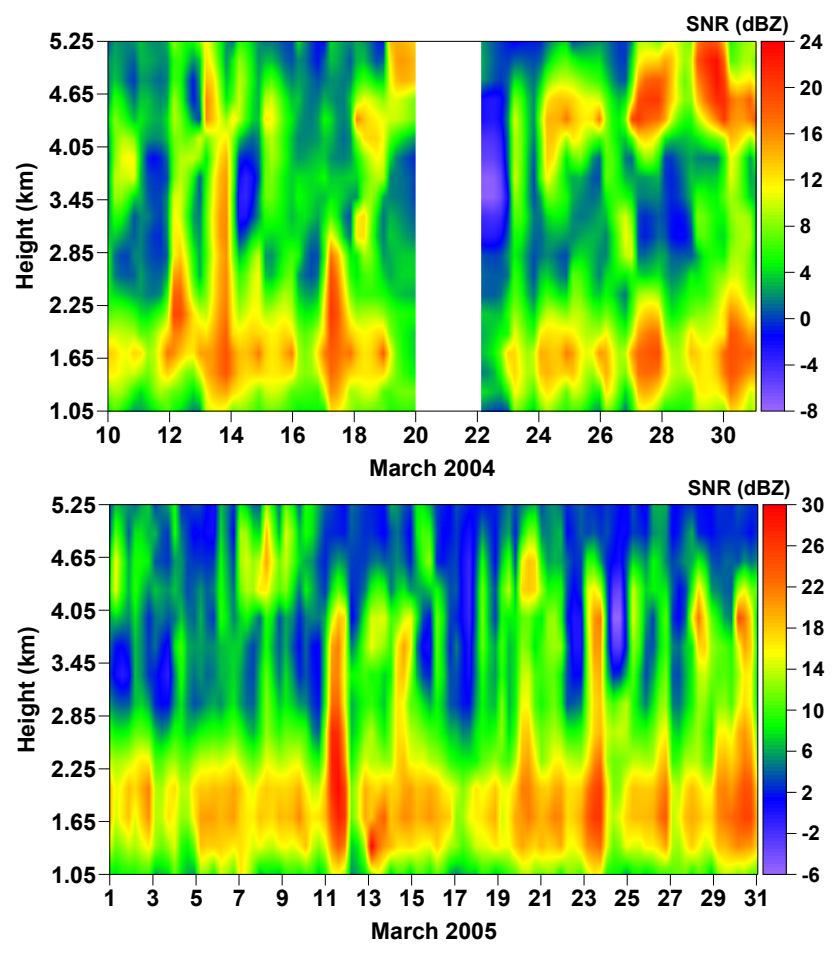

Fig. 8. Time-height cross sections of Wind Profiler-derived Signalto-Noise Ratio (dBZ) in March 2004 (top panel) and in March 2005 (bottom panel).

becoming high. Subsidence motion on the other hand inhibits this ventilating effect and heat transport, causing rise in surface temperatures. In the subsidence the air is warmed by dry adiabatic lapse rate. The atmosphere becomes stable and convection free. Absence of clouds during such occasions leads to increase in incoming solar radiation at the surface and hence the combined effect will increase the surface temperature. To support this observation further, corresponding signal-to-noise (SNR) values obtained from Pune Wind Profiler during the months of March 2004 and 2005 are taken and time-height contour plot similar to Fig. 6 are shown plotted in Fig. 8. An interesting evidence of vertical heat transport can be seen here. Comparing top panel (March 2004) with bottom panel (March 2005), one can see the dominant "thermal plumes" (vertical bands of enhanced SNR) occurring almost daily during March 2005. These plumes seem to extend from about $1 \mathrm{~km}$ to beyond $3.5 \mathrm{~km}$ sometimes. They are more systematically formed and vertically distributed during 2005 than during 2004. During 2004 these thermals apparently seem to be inhibited, possibly by dominant descending motions, from extending into upper levels.

The sun warms the ground, and the ground in turn warms the layer of air nearest to it. As soon as a parcel of air is warmer than its surroundings, it starts trying to rise. Since the ground is not uniform, some parts are darker and/or drier and heat up faster, and some parts are moister or lighter in
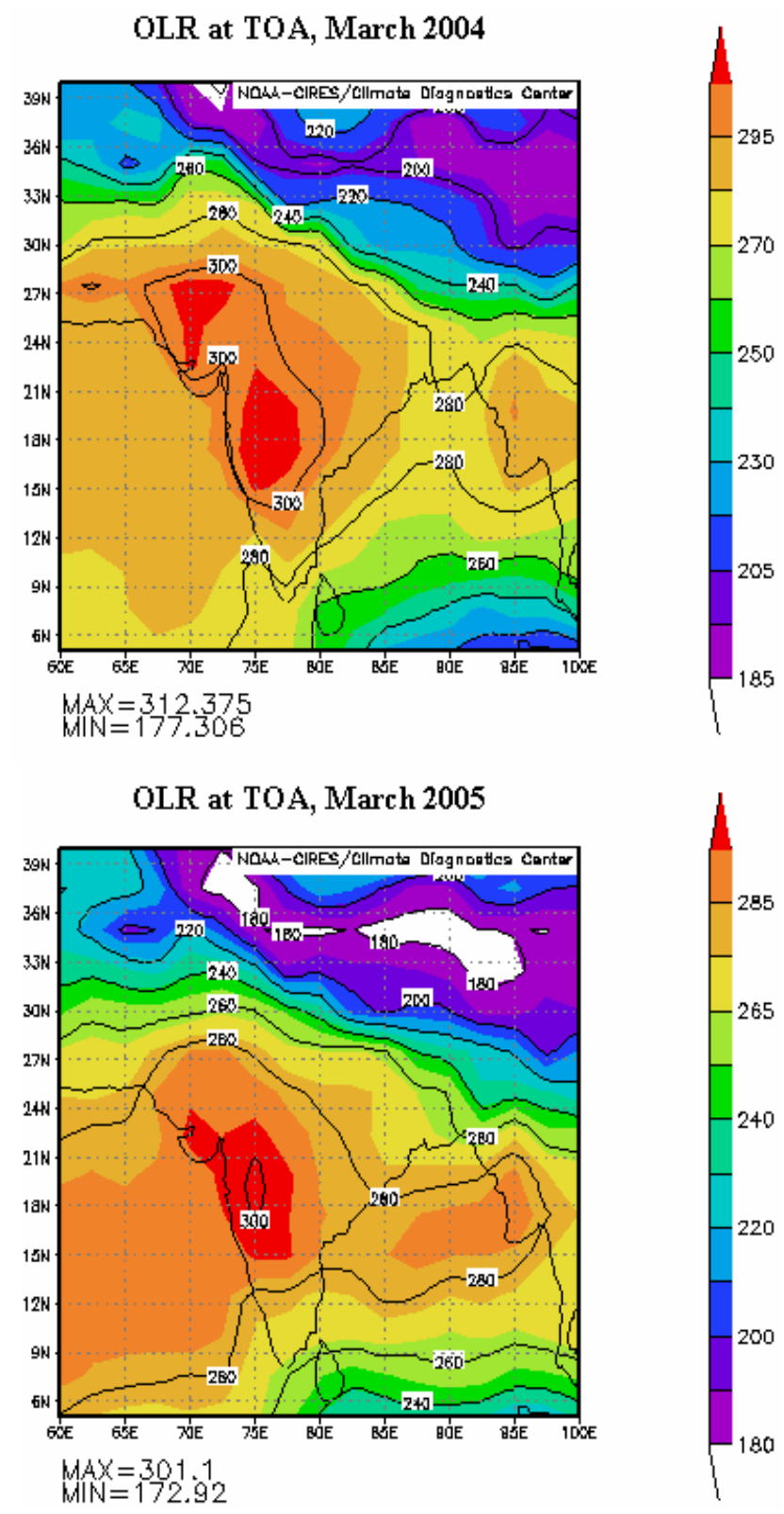

Fig. 9. Spatial distribution of monthly mean outgoing long wave radiation flux $\left(\mathrm{W} / \mathrm{m}^{2}\right)$ at top of the atmosphere over the Indian subcontinent region for March 2004 (top panel) and March 2005 (bottom panel).

color. This result in blobs (parcels) of air forming, rising, and pushing other parcels out of the way. Some of those parcels end up at the ground, get warmed up, and would rise again. Such turbulent motion leads to small 'plumes' of varying shapes and sizes of rising and sinking air. Some of the rising parcels meet up with others and form larger blobs; others get torn apart by turbulence and lose their identity. The size of parcels in the surface layer is roughly proportional to their distance from the surface. The plumes converge as 


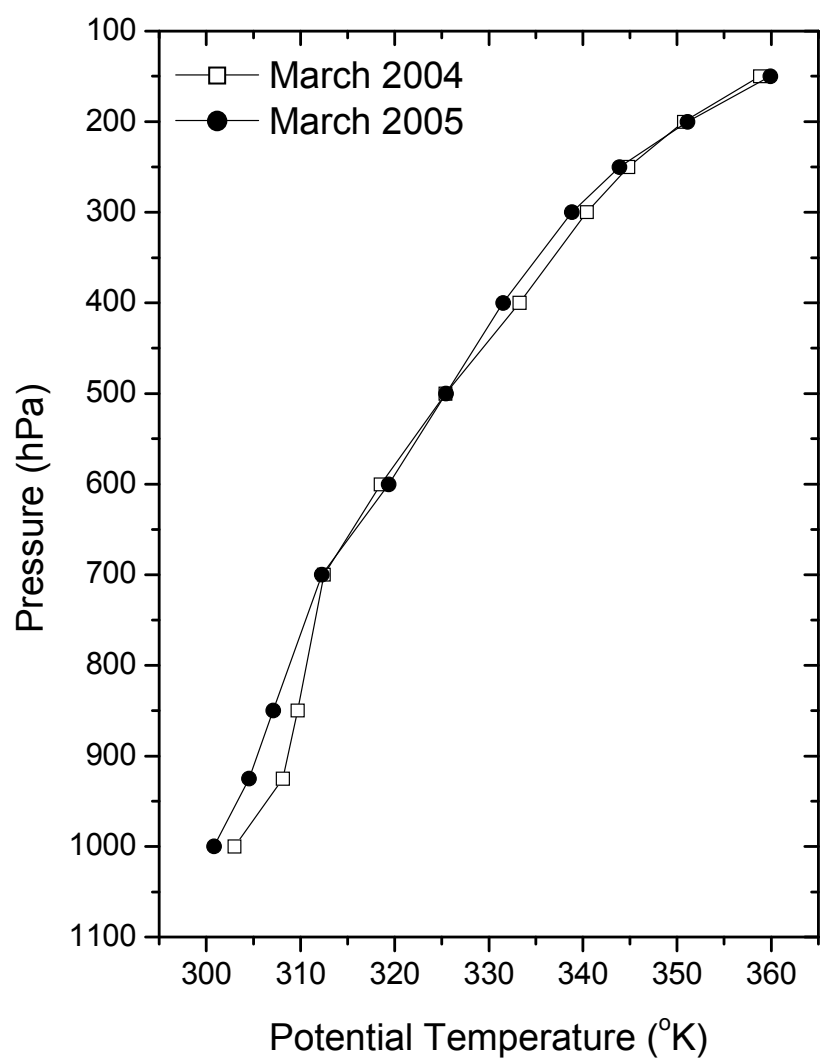

Fig. 10. Monthly mean (for March) altitude profiles of potential temperature for 2004 and 2005.

they rise. By the time they reach the top of the surface layer, 100-200 $\mathrm{m}$ above the ground, they have joined into relatively large columns of rising air. The size of thermals in the mixed layer is roughly proportional to the boundary layer height, so the columns are a few hundred meters to as much as a couple of kilometers in diameter. Thermals are a degree or two Celsius warmer than the surrounding air, and they rise at $1-3 \mathrm{~m}$ per second. These thermal plumes appear as regions of enhanced return echo or SNR at VHF/UHF radio frequencies. In the present case study, evidence of thermals during March 2005 points out that heat from surface layers is being dissipated more efficiently causing surface temperatures to be on the lower side relatively.

Spatial distribution of monthly mean values of Outgoing Longwave Radiation (OLR flux in $\mathrm{W} / \mathrm{m}^{2}$ ) at top of the atmosphere for the Indian subcontinent region $\left(60^{\circ} \mathrm{E}\right.$ to $100^{\circ} \mathrm{E}$ and $6^{\circ} \mathrm{N}$ to $40^{\circ} \mathrm{N}$ ) for March 2004 (top panel) and March 2005 (bottom panel) has been taken from NOAA-CIRES (images provided by the NOAA-CIRES Climate Diagnostics Center, Boulder, Colorado, on their Web site at http: //www.cdc.noaa.gov) and shown in Fig. 9. It is seen that a region of enhanced OLR lies in the west/north-west Indian region and the region of maximum OLR encloses the Wind Profiler station (Pune). The spatial extent of OLR having flux values greater than $300 \mathrm{~W} / \mathrm{m}^{2}$ is relatively much larger during March 2004 compared to that in March 2005. Moreover, the maximum OLR during March 2004 over this region was higher $\left(312 \mathrm{~W} / \mathrm{m}^{2}\right)$ compared to that in March 2005 $\left(301 \mathrm{~W} / \mathrm{m}^{2}\right)$. Daily mean values of potential temperature at surface for a grid point located nearest to Pune for the month of March in 2004 and 2005, taken from NCEP/NCAR Reanalysis (http://www.cdc.noaa.gov/cdc/data.ncep.reanalysis. $\mathrm{htm}$ ) shows that potential temperature at surface is also high on all days of March 2004. Figure 10 shows monthly mean (for March) altitude profiles of potential temperature during the two years for comparison. It is found that atmosphere between $1000 \mathrm{hPa}$ and $900 \mathrm{hPa}$ shows more stable conditions during March 2004 compared to March 2005. Thus all these parameters show contrasting behavior during the month of March in the two years and support that heat wave like conditions prevailed over this station and adjoining region during March 2004. A combination of such process like meridional transport/advection of heat, strong subsidence (downward vertical motion) in the lower troposphere, absence or infrequent occurrence of thermal plumes during daytime etc. might have led to the observed sustained above normal surface temperatures akin to heat wave conditions during March 2004 over the station and in most parts of India.

\section{Conclusions}

The study has brought out the role of Wind Profiler derived vertical velocities in the lower troposphere on the surface temperature variability over a station, representative of semi-arid region, during March 2004 and March 2005. The mean structure of the vertical circulation of the atmosphere in both the cases is compared. The altitude profiles of vertical wind velocities showed different behavior in two contrasting years 2004 and 2005. It is observed that for a major part of the month and at all heights downward motions (subsidence) dominate during March 2004. Strong downward motions persisted for periods of 2-3 days in March 2004. These are the periods when high surface temperatures (above $38^{\circ} \mathrm{C}$ ) were recorded over this station. While March 2005 showed the persistence of upward motion for longer time duration during morning hours which prevents the surface temperatures reaching high values and weak subsidence during afternoon hours. This is supported by observation of more frequent and organized thermal plumes extending right into the free troposphere. Surface temperature anomalies are found to be proportional to the depth of the atmospheric column over which the subsidence occurs. There are distinct episodes of advective warmings during March 2004 while March 2005 showed weak or absence of temperature advection from north to south. Hence a combination of processes like meridional transport of heat, persistent subsidence (downward vertical motion) in the lower troposphere, absence or infrequent occurrence of thermal plumes 
during daytime seemed to have led to the observed above normal surface temperatures akin to heat wave conditions during March 2004 over the station. Thus the high resolution Wind Profiler measured vertical velocities can be used effectively to understand the maintenance and sustenance of long spells of above normal temperatures. Meteorologists in general characterise heat wave intensity looking at large scale patterns of geopotential height or stream function and temperature at the top of boundary layer. However the response on surface variables is not always the same and there seems to be a combination of other regional scale and local factors that can contribute to extreme high surface temperatures. The present study points out that the level of subsidence is one of these.

Acknowledgements. The authors wish to thank the Director, Indian Institute of Tropical Meteorology for his encouragement and R. R. Joshi, J. R. Kulkarni, G. B. Pant, P. C. S. Devara for useful discussions. Support from India Meteorological Department (IMD), Pune in acquiring the Wind Profiler data is gratefully acknowledged. Authors thank the two anonymous referees for their useful suggestions and comments which helped to bring a better shape to the manuscript.

Topical Editor F. D'Andrea thanks two anonymous referees for their help in evaluating this paper.

\section{References}

Atlas, D.: Radar in Meteorology, Amer Meteor Soc, Boston, 1990. Balafoutis, Ch. J. and Makrogiannis, T. J.: Analysis of a heat wave phenomenon over Greece and it's implications for tourism and recreation, Proceedings of the First International Workshop on Climate, Tourism and Recreation, October 2001, Porto Carras, Greece, 2001.
Barth, M.: Evaluation of real time quality control techniques applied to sub hourly Wind Profiler data, 9th symposium on Meteorological observations \& instrumentation, 27-31 March 1995, Charlotte, NC, 1995.

Black, E., Blackburn, M., Harrison G., Hoskins, B., and Methven J.: Factors contributing to the summer 2003 European heatwave, Weather, 59(8), 217-223, 2004.

Chaudhury, S. K., Gore, J. M., and Sinha Ray, K. C.: Impact of heat waves over India, Current Sci., 79, 153-155, 2000.

Deshpande, S. M., Kulkarni, J. R., Joshi, R. R., Singh, N., Damle, S. H., and Pant, G. B.: Atmospheric subsidence and the surface temperature variability in the pre-monsoon month over a semi arid north peninsular Indian station: A case study, Indian J. Radio Space Phys., 36, 33-43, 2007.

Fischer, M. A. and Bolles, R. C.: Random Sample consensus: A paradigm for model fitting with application to image analysis and automated cartography, Commune Assoc Computational Mathematics, 24, 381-395, 1981.

Gage, K. S.: On the scattering and reflection mechanism contributing to clear air echoes from troposphere, stratosphere and mesosphere, Radio Sci., 15, 243-257, 1980.

Grazzini, F., Ferranti, L., Lalaurette, F., and Vitard, F.: The exceptional warm anomalies of summer 2003, ECMWF Newsletter, No. 99, 2-8, 2003.

Holton, J. R.: An Introduction to Dynamic Meteorology, Academic Press Inc., USA, 1992.

Pant, G. B., Joshi, R. R., Damle, S. H., Deshpande, S. M., Singh, N., Vashistha, R. D., Neekhra, P., Chande, J. V., Kulkarni, A. A., and Pillai, J. S.: Wind Profiler and Radio Acoustic Sounding System at IMD, Pune: Some Preliminary Results, Current Sci., 88, 761-769, 2005.

Racz, Z. and Smith, R. K.: The dynamics of heat lows, Q. J. Roy. Meteor. Soc., 122, 1-22, 1999.

Rodwell, M. J. and Hoskins B. J.: Subtropical anticyclones and summer monsoon, J. Climate, 14, 3192-3211, 2001. 